\title{
LA UTOPÍA DE LA CIUDADANÍA UNIVERSAL: LOS DERECHOS DE LAS MINORÍAS SEXUALES HETERODOXAS
}

\author{
Enrique Viana Suberviola ${ }^{1}$ \\ Víctor Fernández Salinas ${ }^{2}$
}

\section{Resumen}

La homosexualidad ha experimentado diversas condiciones legales y sociales a lo largo de la historia. El proceso no ha sido lineal, de forma que se han sucedido épocas de aceptación social con épocas de oscurantismo intolerante. El presente estudio analiza la evolución legal de la homosexualidad en la historia y su relación con la utopía de la consecución de la ciudadanía universal y la igualdad del género humano. La adquisición de los derechos de las minorías fortalece a la sociedad en su conjunto y el pensamiento utópico alimenta la constancia necesaria para poder convertir a nuestras sociedades en entornos igualitarios y justos.

Palabras clave: Utopía; homosexualidad; cambio social; derechos humanos.

\section{A UTOPIA E A CIDADANIA UNIVERSAL: OS DIREITOS DAS MINORIAS SEXUAIS HETERODOXAS}

\section{Resumo}

A homossexualidade tem experimentado diversas condições jurídicas e sociais ao longo da história. O processo não tem sido linear, de modo que tem sucedido épocas de aceitação social com épocas de obscurantismo intolerante. Este estudo analisa a evolução legal da homossexualidade na história e sua relação com a utopia da consecução da cidadania universal e a igualdade de gênero humano. A aquisição dos direitos das minorias fortalece a sociedade em seu conjunto e o pensamento utópico alimenta a constância necessária para poder converter nossas sociedades em contextos igualitários justos.

Palavras-chave: Utopia; homossexualidade; mudança social; Direitos humanos.

\footnotetext{
${ }^{1}$ Doctor en Geografía por la Universitat de Barcelona. Email: enriviana@gmail.com

${ }^{2}$ Profesor Titular de la Universidad de Sevilla. Email: salinas@us.es
}

Sociedade e Território - Natal. Vol. 28, N. 2, p. 7 - 22. Jun./Dez. de 2016 


\title{
THE UTOPIA OF UNIVERSAL CITIZENSHIP. THE RIGHTS OF HETERODOX SEXUAL MINORITIES
}

\begin{abstract}
Homosexuality has experienced various legal and social throughout history conditions. The process has not been linear, so that there have been times of social acceptance intolerant times of obscurantism. This study analyzes the legal evolution of homosexuality in history and its relationship with the utopia of achieving universal citizenship and equality of mankind. The acquisition of minority rights strengthens society as a whole and utopian thinking feeds the evidence needed to turn our societies into egalitarian and fair environments.
\end{abstract}

Keywords: Utopia; homosexuality; social change; human rights.

\section{PLANTEAMIENTOS DE PARTIDA}

El grupo o colectivo que es objeto de este estudio es el habitualmente denominado GLBTI (gays, lesbianas, bisexuales, transexuales e intersexuales; LGBTI en su acrónimo en inglés), que incluye, de forma genérica, a aquellas poblaciones que se apartan de la ortodoxia sexual que podría denominarse tradicional y que realizan conductas sexuales que, en consecuencia, pueden ser calificadas de heterodoxas. Se prefiere la utilización de la palabra conducta a la de práctica dado que la expresión sexual no se concibe únicamente como una actividad genital, sino como un compendio de actitudes y acciones, entre ellas las sexuales, que enfrentan a esta comunidad, no solo a la manera de concebir el sexo, sino de enfrentarse a los valores de una sociedad en la que la imposición de la heterosexualidad exclusiva también implica la asunción de una serie de preceptos, ideologías y pautas sociales que afectan negativamente a quien no las asume.

La evolución de la aceptación de la heterodoxia sexual es percibida habitualmente como un proceso lineal y sin aristas. Sin embargo, al considerarlo en una perspectiva metodológica psicológica, los argumentos adquieren otro valor y, sobre todo, una lectura espacial mucho menos simple en el planeta. La abundancia de estudios sobre el mundo homosexual se ha incrementado notablemente durante los últimos decenios, pero no se trata solo de un aumento cuantitativo, sino también cualitativo. La investigación ha seguido, y formado parte, de una estrategia reivindicativa de derechos para un colectivo determinado, aunque en sí mismo muy indeterminado, por cuanto que no se trata de un grupo homogéneo en sí, ni en sus intereses (HEINZE, 1995). La propia evolución de este carácter reivindicativo 
se hace más compleja por su carácter inclusivo, de manera que desde casi su principio en los años setenta ha ido incorporando grupos cuyo denominador común se encuentra en la negación de la simplicidad sexual hombre-mujer y que incluyen, además de los homosexuales masculinos, con los que se inicia el proceso, a lesbianas, bisexuales, transexuales, lesbianas, queer y un largo etcétera que ha ido obligando a utilizar acrónimos cada vez más largos y no siempre más explícitos.

La percepción de una realidad social como es la homosexualidad tiende a modificarse en función de la situación social y política que se viva en cada momento. La modificación de dicha percepción puede comportar, y de hecho lo hace, cambios jurídicos y legales. La homosexualidad, por ser un tipo de orientación minoritaria y obligada a ser invisible, tiende a ser muy vulnerable y los derechos adquiridos en materia sexual y afectiva pueden verse revocados de forma abrupta en función de la realidad social existente. Por ello son importantes los estudios sobre la situación legal de las minorías, en especial de las minorías sexuales, ya que dichos estudios muestran la realidad democrática de una sociedad. El pionero informe Kinsey abrió puerta a muchos otros estudios sobre la sexualidad (DOVER, 1978), aunque la gran mayoría de ellos, al ser tratados desde la óptica de la sociología, el derecho y la medicina ${ }^{3}$, obviaban el componente espacial (BELL, 1979). La geografía, que ha incorporado esta visión y surge fundamentalmente en los países anglosajones, ha generado desde hace ya varios decenios una abundante producción sobre la situación de las minorías sexuales en el planeta (BELL, 1995). Los orígenes del interés pueden plantearse desde aspectos ligados al comunitarismo (BALL, 1999.); la identidad sexual gay, lesbiana, bisexual, transexual e intersexual. O, sobre todo, respecto a los derechos civiles ${ }^{4}$. A estos efectos, son particularmente interesantes los Principios de Yogyakarta en 2006 respecto a la obligación de los estados de reconocer y proteger los derechos relacionados con la orientación sexual y la identidad sexual de sus ciudadanos.

A los propósitos de este artículo se utiliza, fundamentalmente por la obligación que imprimen las fuentes disponibles, una terminología que puede ser calificada de heterodoxa,

\footnotetext{
${ }^{3}$ AlventosadelRío, 2005; AmichElías, 2007; BañosLemoine, 2008; Bonilla Sánchez, 2013; Castañeda, 2006; Fernández Salinas, 2007; Heinze, 1995; Knopp, 2004; Kondakov, 2010; López Sánchez, 2006; Martel, 2014; Segura Gutiérrez, 2007; Serena, 2014; Valdeón García, 1997.

${ }^{4}$ Amich Elías, 2007; Etxazarra 2007; Fernández-Coronado González, 2006; Gates, 2013; Gimeno y Barrientos, 2009; Heinze, 1995; Hubbard, 2013; León-Castro Alonso, 2013; Muñoz Catalán, 2013; Nuevo, 2006; Stychin, 2003.
} 
puesto que en ocasiones se hará referencia a aspectos que atañen a la comunidad en su conjunto (GLBTI) y otras tan solo a las conductas de homosexuales varones. Esto, que una primera impresión pudiera dar sensación de debilidad conceptual y metodológica, se revela una ventaja, debidamente ponderada la información, al aplicar el conocimiento a un proceso cuyo reconocimiento ha sido asimétrico y carente de homogeneidad.

Por otro lado, también hay que considerar que la utilización de la expresión homofobia o sus derivados se refiere en este artículo no solo al rechazo de las conductas homosexuales, sino a toda expresión de heterodoxia sexual propia de la conducta de los grupos GLBTI.

\section{LA UTOPÍA DE LA CIUDADANÍA UNIVERSAL}

Uno de los primeros utópicos que defendían la idea de una sociedad perfecta fue Platón. El filósofo plasmó en La República un Estado en el que primase la justicia y el bien social. Ya en aquel entonces, Platón argumentaba que debían ser los sabios los que gobernasen a la sociedad. El triunfo del sentido común sobre la fuerza bruta. Más tarde, durante el Renacimiento, Tomás Moro ahondó en esta cuestión en su obra Utopía, en la que, al igual que Platón, eran los más preparados y sabios los que gobernaban a la sociedad. Ambos autores imaginaban una sociedad regida por el derecho y el raciocinio y despojaba de autoridad a los oligarcas nepotistas de la época.

Estas bases fundamentales del conocimiento humano fueron precursoras de los movimientos políticos y sociales que se produjeron a finales del siglo XVIII cuando la Revolución francesa puso fin a la era moderna y dio paso a la era contemporánea en la que nos encontramos. Uno de los adalides ideológicos de dicho período fue Jean-Jacques Rousseau que con El origen de la desigualdad entre los hombres (1755) acentuó la crítica a la sociedad de entonces y propuso un modelo basado en un idealismo de igualdad y justicia social.

Justo en esa época se empezaban a truncar los valores existentes. La revolución francesa cimentó los derechos de la sociedad y del individuo y fue en esa misma época en la que se advirtió que el comportamiento sexual realizado en privado y con consentimiento de las diferentes partes involucradas era un asunto de carácter íntimo que no debía ser castigado por la ley. La homosexualidad fue aprobada en Francia a finales del siglo XVIII y durante un breve período de tiempo por los países y territorios conquistados por Napoleón. 
Posteriormente, durante el siglo XX, fue el socialismo utópico el que ensalzó el idealismo social como bandera. Durante el gobierno de Lenin la homosexualidad fue legalizada en la U.R.S.S., uno de los países más avanzados y liberales del mundo a comienzos de siglo.

Una vez finalizada la Segunda Guerra Mundial, las diferentes naciones, horrorizadas por los desastres acaecidos decidieron promulgar la Declaración de los Derechos del Hombre de 1948, en cuyos artículos 1 y 2 se indica lo siguiente: Toda persona tiene los derechos y libertades proclamados en esta Declaración, sin distinción alguna de raza, color, sexo, idioma, religión, opinión política o de cualquier otra índole, origen nacional o social, posición económica, nacimiento o cualquier otra condición. Esta declaración libertaria e igualitaria dio rienda suelta a los movimientos a favor de la igualdad de las personas homosexuales y transexuales que en décadas posteriores alcanzaron la plenitud de derechos civiles. Las utopías de Rousseau, Moro y Platón se van aproximando a la realidad gradualmente.

\section{UTÓPICOS MODERNOS Y DERECHOS HUMANOS}

Los movimientos de liberación de la mujer y el movimiento abolicionista de la esclavitud, ambos del siglo XIX comenzaron a pergeñar un cambio social cada vez más acentuado. Comenzaba a vislumbrarse claramente cómo los derechos del individuo debían protegerse y fomentarse en pos del fortalecimiento social en su conjunto.

Una vez finalizada la Segunda Guerra Mundial, se hizo necesario promulgar la Declaración de los Derechos del Hombre en 1948, para dotar al mundo de un instrumento legal que favoreciese los derechos individuales de las personas.

El movimiento LGBTI es el último exponente de este proceso de defensa del individuo y tuvo su pistoletazo inicial oficialmente en 1969 durante los disturbios de Stonewall en Nueva York. A partir de ese punto y con grandes dificultades sociales y legales, se han ido adquiriendo grandes hitos hasta llegar a la situación actual en la que se observa un mundo polarizado.

A esta lucha por la adquisición de una sociedad más libre se han unido diversos actores provenientes de ámbitos muy dispares. Desde el ex Secretario General de las Naciones Unidad, Kofi Annan, que reclamó públicamente la apertura de un debate acerca de la situación legal del colectivo LGBTI, hasta Amnistía Internacional, que con su campaña Mi 
cuerpo, mis derechos ha abogado por la abolición de las leyes que criminalizan la homosexualidad y transexualidad en el mundo.

Otros actores que se han pronunciado al respecto han sido Desmond Tutu, líder del movimiento anti-apartheid de Sudáfrica, que se ha referido al colectivo LGBTI de la siguiente manera:

\begin{abstract}
Un padre que educa a un hijo para ser racista está perjudicando al niño, está perjudicando a la comunidad en la que viven, está perjudicando nuestras esperanzas de un mundo mejor. Un padre que enseña a un niño que sólo hay una orientación sexual y que todo lo demás es malvado está negando nuestra humanidad y la suya también. No podemos responder al odio con odio. Sólo podemos responder con amor, comprensión y confianza y compromiso con la justicia (BAIRD, 2004, p. 10).
\end{abstract}

El fenómeno de la defensa de los derechos sexuales es tan amplio y transversal, que otro líder comunitario cuyas acciones y carácter son radicalmente diferente también se ha pronunciado al respecto. Se trata del subcomandante Marcos, uno de los líderes del Ejército Zapatista de Liberación Nacional, que se pronunció al respecto:

Los y las zapatistas, y quienes no son los ni las, pero son zapatistas, saludamos la dignidad lésbica, gay, transgenérica y bisexual. Larga vida a su combatividad y un mañana distinto, es decir, más justo y humano, para todos y todas los diferentes (BAIRD, 2004, p. 169).

El movimiento LGBTI ha traspasado las barreras nacionales y personales. En el pensamiento colectivo, comienza a vincularse, cada vez con más fuerza la adquisición de los derechos de las minorías como la condición sinequanom para conseguir el ideario social. La utopía de una sociedad libre pasa, de este modo, por la adquisición de las libertades del individuo en todas sus dimensiones.

\title{
SITUACIÓN LEGAL DE LA HOMOSEXUALIDAD
}

En este apartado se hace referencia a la evolución histórica que ha tenido el tratamiento legal de la homosexualidad así como la situación legal de la misma en la actualidad. 


\section{Evolución histórica de la situación legal de la homosexualidad}

La homosexualidad ha tenido diferentes consideraciones sociales y legales a lo largo de la historia (Figura 01). Ha habido momentos en la historia más permisivos con las relaciones sexuales no mayoritarias y otros en los que la homosexualidad ha sido duramente perseguida.

Hay países en donde la homosexualidad nunca ha sido oficialmente perseguida por las leyes. Países como Corea, el sudeste asiático, Bolivia, el África subsahariana francófona o Polonia han sido nichos de tolerancia en un mundo cambiante.

Figura 01: Fecha de legalización de la homosexualidad por países.

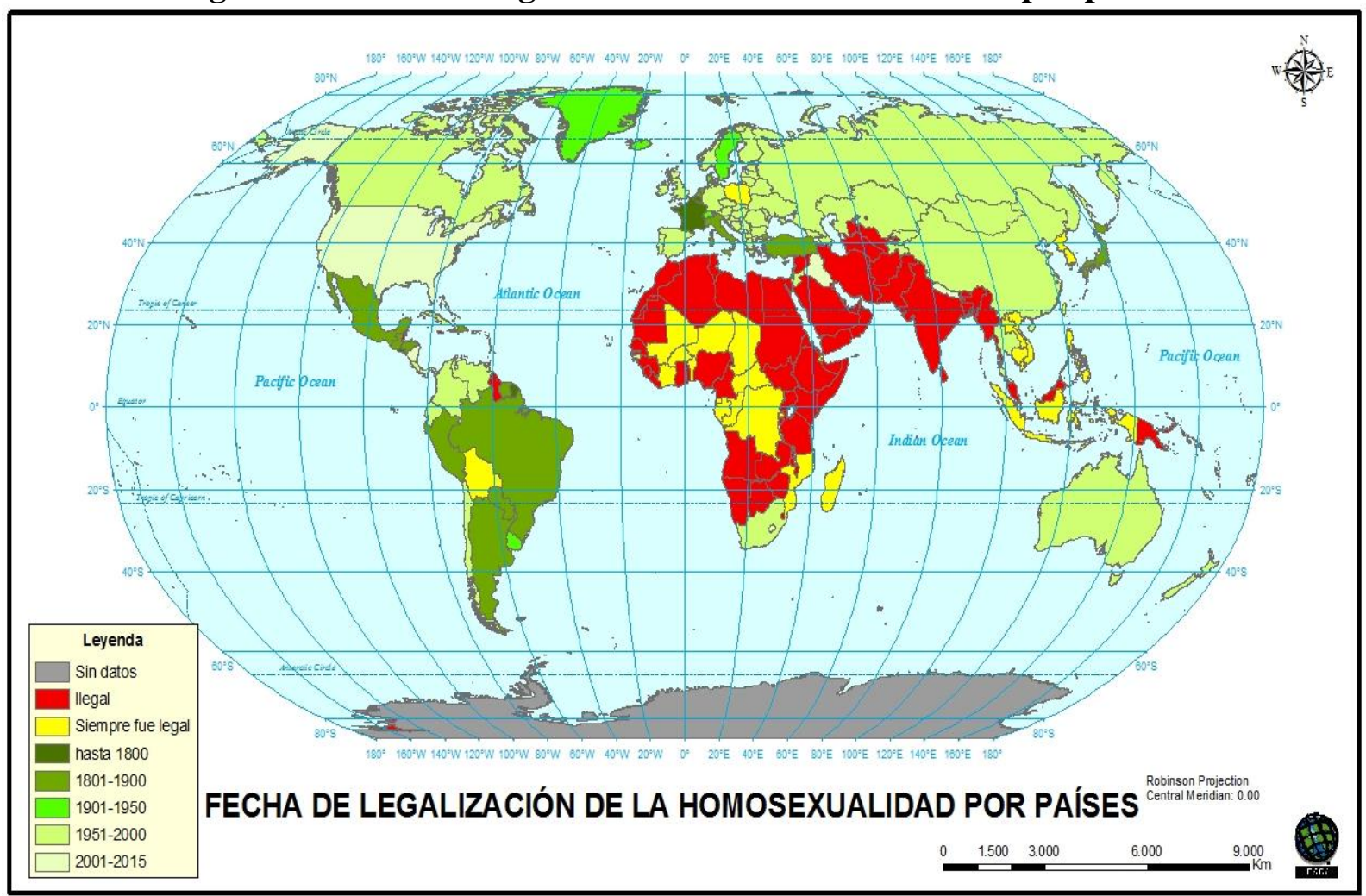

Fuente: elaboración propia a partir de ILGA y Wikipedia.

Los países en donde la homosexualidad se legalizó definitivamente tuvieron una evolución ascendiente desde finales del siglo XVIII, cuando a raíz de la Revolución francesa se propugnaron los valores de la Ilustración y se despenalizó la sodomía en Francia, Bélgica y, de forma temporal, en los territorios conquistados por Napoleón, como por ejemplo España, donde la homosexualidad fue legal durante un breve período de inicios del siglo XIX. 
Durante todo el siglo XIX pocos fueron los países que legalizaron la homosexualidad. Entre ellos estaba Turquía, Italia, Japón (este país ilegalizó durante unos años la homosexualidad durante la época Meiji para congraciarse con la conservadora sociedad occidental pero la presión popular obligó a su relegalización), y sobre todo buena parte de los Estados latinoamericanos que se independizaron de España y adoptaron en parte, como base legal el código napoleónico en el que la homosexualidad era legal.

Durante la primera mitad del siglo XX fueron aún menos los países que legalizaron la homosexualidad. Entre ellos estaban Suecia, Suiza, Dinamarca, Islandia y Uruguay.Pero sin embargo, fue durante la segunda mitad del siglo XX cuando se produjeron los avances más importantes en esta cuestión. A partir del año 1969, los disturbios de Stonewall propulsaron las reivindicaciones LGBTI a nivel internacional. La despatologización de la homosexualidad por la Organización Mundial de la Salud en 1991 y la caída del bloque comunista fueron acicates que dieron alas al movimiento de liberación homosexual. Fue en esta época cuando se legalizó la homosexualidad en el resto de Europa, Rusia, China, Sudáfrica, Australia, Nueva Zelanda, Canadá y una parte de América latina.

En EEUU una gran parte de sus Estados legalizaron la homosexualidad de forma paulatina pero no fue hasta el año 2003 cuando se legalizó a nivel nacional.

Actualmente, en cerca de 200 Estados que componen el mundo hay más de 70 países que condenan la homosexualidad masculina y más de 50 Estados que criminalizan las relaciones lésbicas.

\section{Situación legal de las personas LGBTI en la actualidad}

La situación legal de las personas LGBTI es altamente compleja y diversa (Figura 02). Existen países en donde los homosexuales se pueden casar y otros en donde se les condena a muerte por sentir como sienten.

En este complejo puzzle se hallan los países que otorgan los derechos de matrimonio y unión civil a las parejas homosexuales. En esta categoría se halla buena parte de América (EEUU, Canadá, Brasil, Uruguay, Argentina y Colombia) y Europa occidental (Escandinavia, Benelux, Francia, España, Irlanda) así como Sudáfrica y Nueva Zelanda. Sin embargo, algunos países sólo reconocen al matrimonio homosexual en algunas áreas de su territorio 
(México, Reino Unido) o simplemente no lo contemplan en su legislación pero reconocen los matrimonios y uniones homosexuales realizadas en países extranjeros (Israel).

En un segundo bloque de aceptación se hallan los países que otorgan a los homosexuales la posibilidad de unirse únicamente en uniones civiles. Entre ellos se hallan diversos países de América (Chile, Costa Rica, Ecuador), Europa (Alemania y Europa central), y Oceanía (Australia). Algunos países como Australia solo aceptan las uniones civiles en determinadas áreas de su territorio y otros países como Croacia tienen una legislación ambigua.

Figura 02: Situación legal de las personas LGBTI en 2016.

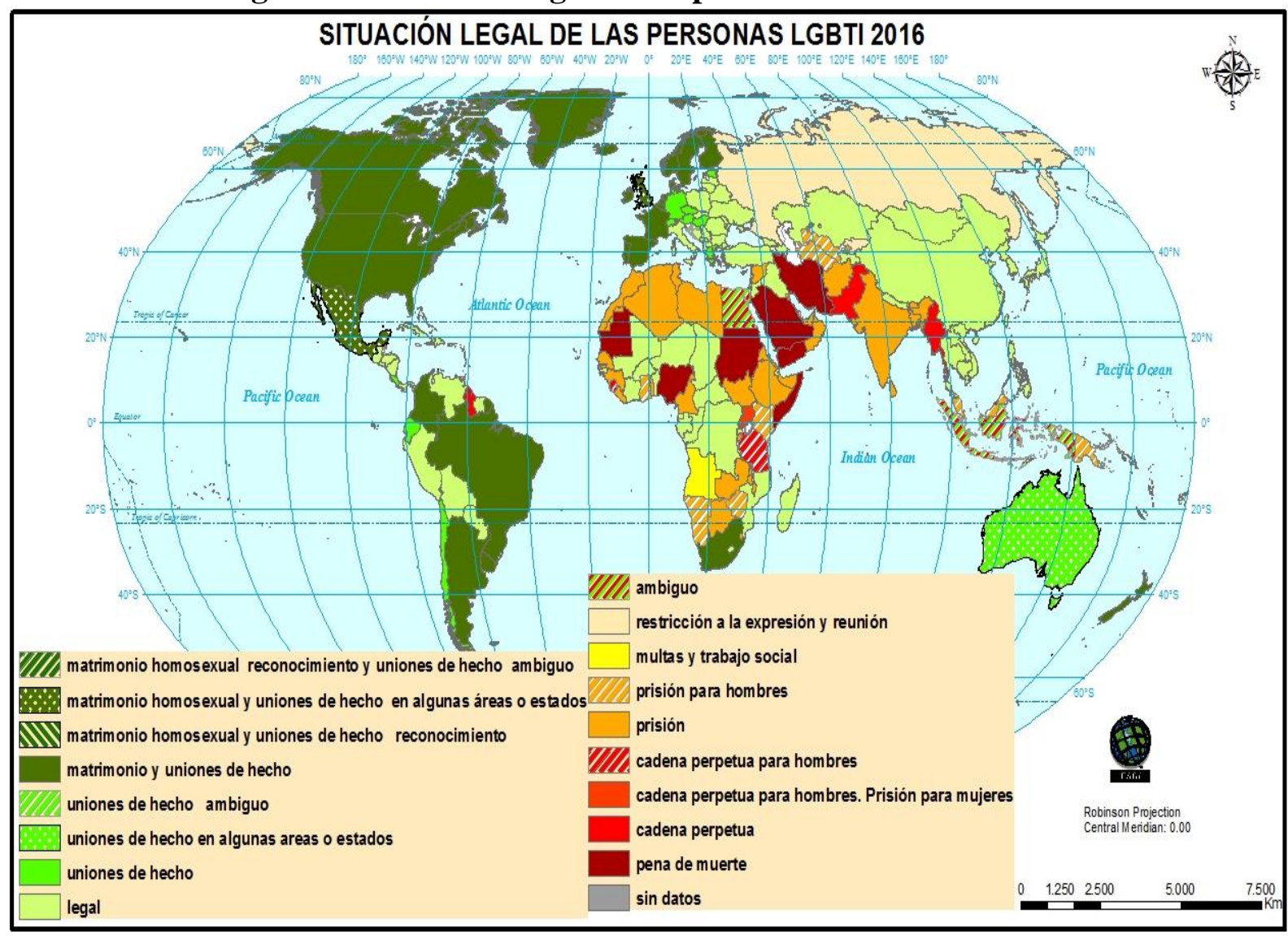

Fuente: elaboración propia a partir de ILGA y Wikipedia.

En un tercer bloque de aceptación se hallan los países que no criminalizan a la homosexualidad pero tampoco protegen a las personas LGBTI con los mismos derechos y obligaciones que disfrutan las parejas homosexuales. En realidad se trata de una situación de alegalidad. Los países que conforman este bloque son Centroamérica y el Caribe, Perú y 
Bolivia en América, Europa central y los Balcanes en Europa, China, sudeste asiático y extremo oriente en Asia, y el África francófona. Algunos países como Egipto e Indonesia tienen leyes ambiguas sobre la legalidad de la homosexualidad. La evolución dicta que todos estos países acaben otorgando a los homosexuales los mismos derechos que poseen la población heterosexual.

En un cuarto bloque de aceptación ya hay que adentrarse en los países que criminalizan de una forma u otra a los homosexuales y transexuales. Rusia ha propugnado una feroz campaña para invisibilizar a la población homosexual impidiendo todo tipo de manifestación pública de la misma. En teoría no existen sanciones legales contra la homosexualidad pero sí contra su visibilización y su promoción como un estilo de vida aceptable. A esta oscura ideología de represión se han sumado buena parte de los países del antiguo bloque soviético, dividiendo profundamente a Europa sobre esta cuestión.

En un quinto bloque de aceptación se hallan los países que criminalizan la homosexualidad con castigos que van desde una multa (Angola) hasta la pena de cárcel, diferenciando en aquellos países que imponen una condena de pocos años (Magreb, India, cono sur de África) hasta la cadena perpetua (Pakistán, Tanzania, Uganda o Mianmar). En este caso resulta bastante curioso el hecho de que muchos de estos países criminalizan la homosexualidad masculina pero no la femenina (Namibia, Zimbabwe, Kenia, Tanzania). Esto se debe en parte a la ignorancia y en parte al machismo. Muchas culturas consideran que si no existe la penetración no existe "sexo real" y por ello el lesbianismo no está tipificado en la legislación.

En el último bloque de aceptación se hallan los países que llamaremos "el eje del mal homofóbico". Países que en su legislación contemplan la pena de muerte para las personas con una sensibilidad sexual diferente. En realidad, estos países sí parecen formar un eje desde Irán, pasando por Arabia Saudí y Yemen hasta Somalia y Sudán y desembocando en Nigeria y Mauritania. Todos ellos impregnados del islam más fanático e intransigente.

En este complejo mundo la aceptación plena de la igualdad entre los seres humanos y la intransigencia más atroz pugnan por ganar un juego de geopolítica. 


\section{LA UTOPÍA DE LA UNIVERSALIZACIÓN DE LOS DERECHOS CIVILES: LA DECLARACIÓN DE LA ONU DE 2008}

En el año 2008, Francia, respaldada por la Unión Europea presentó una resolución ante la ONU (Figura 03) para obligar a los Estados a evitar la criminalización, persecución, hostigamiento, discriminación y maltrato hacia las personas LGBTI. Esta resolución fue firmada por 66 países, principalmente de Europa y América, así como algunos países de Asia, África y Oceanía como Sudáfrica, Japón, Australia, Nueva Zelanda, Corea del Sur, Filipinas y Tailandia.

Figura 03: Declaración de la ONU del año 2008 referente a la legalización de la homosexualidad a nivel mundial.

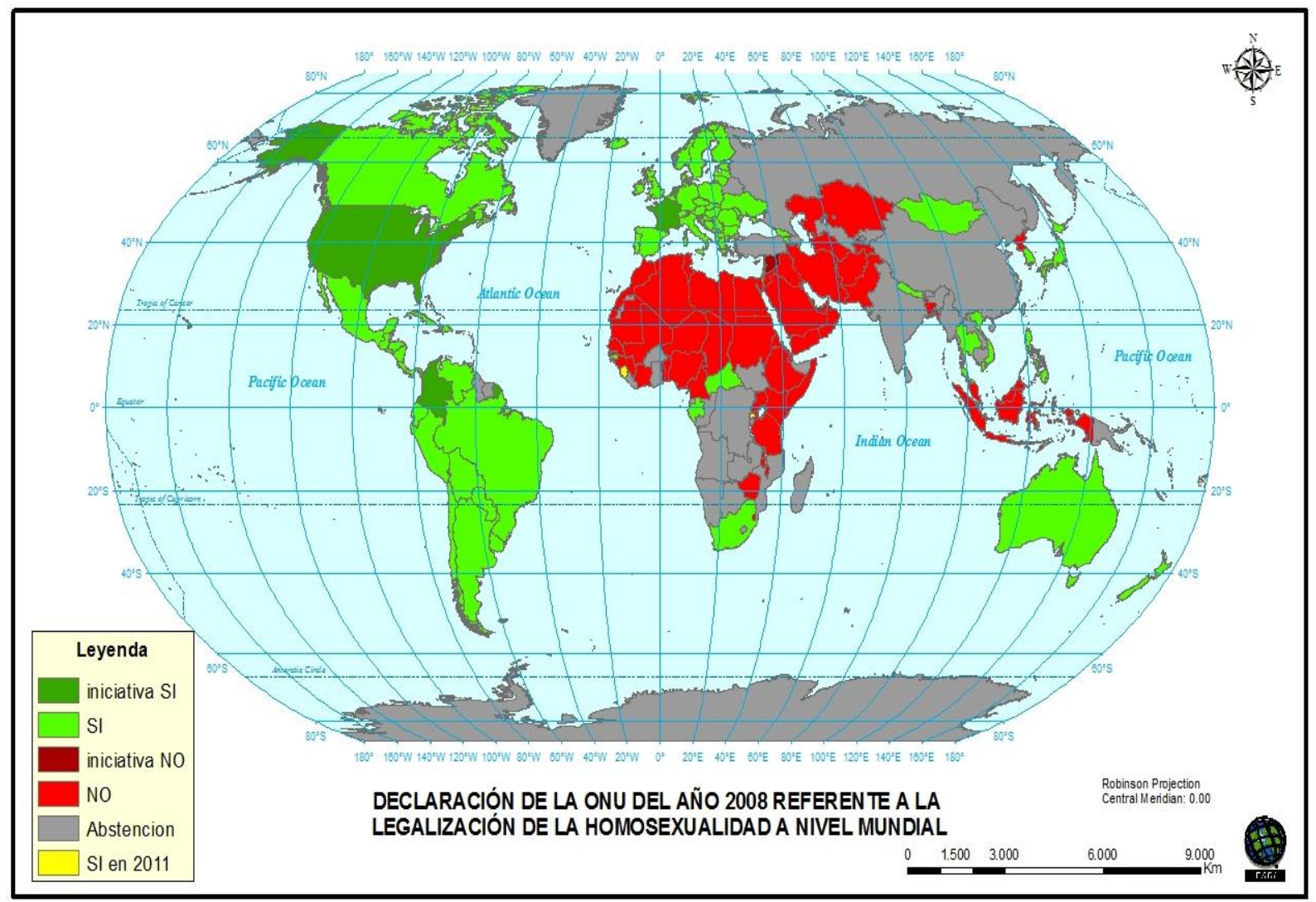

Fuente: elaboración propia a partir de Wikipedia.

Al mismo tiempo, Siria presentó una resolución contraria que persigue seguir criminalizando la homosexualidad. Esta resolución fue firmada por 57 Estados, la inmensa mayoría de confesión islámica. 
A ambas resoluciones se han abstenido importantes países como Rusia, China, India y el cono sur africano.

Estas resoluciones permanecen abiertas y parece difícil que se pueda llegar a una solución definitiva al respecto puesto que las posturas están altamente polarizadas, lo que demuestra la candente situación a la que se enfrenta la población LGBTI en la mayor parte del globo.

Cabe mencionar que en el año 2011, algunos países como Sierra Leona o Ruanda se posicionaron a favor del SI, lo que indica una tímida tendencia a aceptar la resolución favorable a los derechos LGBTI.

En todo caso, es loable la intención del Ejecutivo francés de promover la igualdad de la ciudadanía a todos los niveles. Resulta utópico en esta fase del desarrollo social de la humanidad por cuanto parece existir un choque de culturas o de civilizaciones que impide en buena manera la consecución de la igualdad humana. Más que cualquier otro tema, la homosexualidad y su tratamiento social y legal dibujan claramente el límite existente entre las naciones que apuestan por el respeto a los derechos humanos y aquellas que aún perpetúan la ley del más fuerte.

\section{CONCLUSIONES}

En este complejo mundo la aceptación plena de la igualdad entre los seres humanos y la intransigencia pugnan por ganar un juego de geopolítica. Al igual que ocurrió con la conquista de los derechos de la mujer, los derechos de la población LGBTI comienzan a abrirse paso en las diferentes sociedades del mundo. La mujer, la mitad de la población de la humanidad, tardó más de cien años en transformar la sociedad global y los códigos legales y penales del mundo. La andadura del colectivo LGBTI es mucho más corta aunque el proceso parece imparable. La evolución de esta tendencia en el futuro definirá no sólo la situación del colectivo LGBTI sino la situación de la democracia en el mundo, ya que la democracia y la defensa de los derechos y valores humanos no son un bien asegurado sino que son susceptibles de avanzar y retroceder en función de la situación social y política de las sociedades del mundo.

Uno de los motivos principales por los que la homosexualidad está duramente penada, no responde a criterios de alarma social sino a criterios de orden político y geopolítico. La 
homosexualidad con frecuencia es vista como aquello ajeno a la propia cultura. Los jesuitas del siglo XVI llamaban a la homosexualidad el vicio japonés, los comunistas la tildaban de vicio burgués, los musulmanes y africanos hablan del vicio occidental. Reprimir la homosexualidad es una forma de combatir aquello que se considera externo a la propia cultura, aquello que realiza una injerencia percibida como intolerable por la sociedad. Por ello, la persistencia de la represión a la homosexualidad sigue vigente en grandes áreas del planeta que poseen un conflicto social, político o económico con occidente ya que este se asocia mentalmente con la homosexualidad.

Sin embargo, lo cierto es que la homosexualidad es tan antigua como el ser humano. La forma en la que las diferentes tradiciones y culturas han tratado a la homosexualidad ha sido muy dispar desde el comienzo de los tiempos. La homosexualidad es parte de la naturaleza humana, es parte del entramado social de la humanidad y su represión y negación ha derivado siempre en un empobrecimiento de la calidad democrática del sistema en su conjunto.

Muchos han sido los vaivenes legales y sociales que ha tenido esta diferente forma de amar y sentir, este amor que no osa pronunciar su nombre, como decía Wilde. Actualmente, nos hallamos en un momento único en la historia. Un momento en donde se suceden las mayores barbaries y represiones hacia esta orientación y, por el contrario, la mayor de las aceptaciones. Vivimos en un mundo bipolar, un mundo contrapuesto que se encona mutuamente.

La plena aceptación a nivel mundial tardará décadas, quizá un siglo, aunque parece que el fenómeno lejos de remitir está alcanzando cotas de éxito nunca antes vistas en pos de la igualdad de los hombres.

\section{REFERÊNCIAS}

ALVENTOSA DEL RÍO, Josefina. Matrimonio y adopción por personas del mismo sexo. Madrid: Cuadernos de Derecho judicial, 2005. 632p.

AMICH ELÍAS, Cristina. Cultura homosexual, sujeto homosexual y derechos humanos. Foro: Revista de ciencias jurídicas y sociales. [En línea]. Madrid: Universidad Complutense de Madrid, 2007, no 5, p. 199-219. < http://dialnet.unirioja.es/servlet/articulo?codigo=2561060> . ISSN:1698-5583.

BAIRD, Vanessa. Sexo, amor y homofobia. Londres: Amnistía Internacional UK y Egales Editorial, 2004. 199p. 
BALL, Carlos A. Communitarianism and Gay Rights.Cornell Law. Review: 1999, n 85, p. 443-516.

BAÑOS LEMOINE, Carlos Arturo. Pecado, delito y enfermedad. El estigma de ser homosexual. Notas de sociología crítica a propósito de las uniones homosexuales en América Latina. Revista legislativa de estudios sociales y de opinión pública. [En línea]. España, 2008, vol.1, no 1, p. 45-80. < http://dialnet.unirioja.es/servlet/articulo?codigo=2697168>.

BELL, Allan. P. Homosexualidades informe Kinsey. Madrid: Revista de psicología general y aplicada, 1979. $563 \mathrm{p}$.

BELL, J. Davis. Insignificant Others: Lesbian and Gay Geographies. Area, vol. 23, $\mathrm{n}^{\circ} 4$, 1995. p. 323-329.

BONILLA SÁNCHEZ, Juan José. Sobre la Declaración de Constitucional del matrimonio entre personas del mismo sexo, homosexual o igualitario. Espacio y Tiempo: Revista de Ciencias Humanas. [En línea]. Sevilla: Universidad de Sevilla, 2013, no .27, p. 39-50. < http://dialnet.unirioja.es/servlet/articulo?codigo=4352018>. ISSN: 1885-0138.

CASTAÑEDA, Marina. La nueva homosexualidad. México D.F: Paidos, 2006. 216 p.

DOVER, Kenneth.J. Homosexualidadgriega.MJF Books Fine Communications y Harvard University Press, 1978.380 p.

ETXAZARRA, Leire. La legalización del matrimonio homosexual (el cómo y el porqué de una movilización). Papelesdel CEIC, International Journal on Collective Identity Research. [Enlínea].España, 2007, nº. 1. < http://dialnet.unirioja.es/servlet/articulo?codigo=2254027>. ISSN-e: 1695-6494.

FERNÁNDEZ-CORONADO GONZÁLEZ, Ana. La evolución jurídica del sistema matrimonial español desde la Constitución de 1978 a la admisión del matrimonio homosexual. Foro: Revista de ciencias jurídicas y sociales. [En línea]. Madrid: Universidad Complutense de Madrid, 2006, $\mathrm{n}^{\mathrm{o}}$ 3, p. 96-112. <

http://dialnet.unirioja.es/servlet/articulo?codigo=2188058>. ISSN: 1698-5583.

FERNÁNDEZ SALINAS, Víctor. Comunidad gay y espacio en España. Boletín de la Asociación de Geógrafos Españoles. [En línea]. España, 2007, nº43, p. 241-260. < http://dialnet.unirioja.es/servlet/articulo?codigo=2499270>. ISSN: 0212-9426.

GATES, Gary J. Geography of the LGBT population. International handbook on the demography of sexuality, 2013, no 5, p. 229-242.

GIMENO, Beatriz, BARRIENTOS, Violeta. La institución matrimonial después del matrimonio homosexual. Íconos: Revista de Ciencias Sociales. [En línea]. Costa Rica: Facultad Latinoamericana de Ciencias Sociales, 2009, nº 35, p. 19-30. < http://dialnet.unirioja.es/servlet/articulo?codigo=3318705>. ISSN-e: 1390-1249.

HEINZE, Eric. Sexual orientation: a human right: an essay on international human rights law. Ed: Dordrecht [etc]: MartinusNijhoff, 1995. 440 p. 
HUBBARD, P. Kissing is not a universal right: Sexuality, law and the scales of citizenship.

Geoforum, 2013, n 49, p. 224-232.

INTERNATIONAL LESBIAN, GAY, BISEXUAL, TRANS AND INTERSEX ASSOCIATION - ILGA.Annual reports, 2010, 2011, 2012, 2013, 2014 y 2015.<http://ilga.org/>

KNOPP, L. Ontologies of Place, Placelessness, and Movement: Queer Quests for Identity and Their Impacts on Contemporary Geographic Thought. Gender, Place, and Culture , 2004, $\mathrm{n}^{\circ}$ 11, p. 121-134.

KONDAKOV, Alexander. Heteronormativity of the Russian legal discourse: The silencing, lack, and absence of homosexual subjects in law and policies. Sortuz: Oñati Journal of Emergent Socio-legal Studies. [Enlínea].España, 2010, vol. 4, nº 2, p. 4-23. < http://dialnet.unirioja.es/servlet/articulo?codigo=3715677>. ISSN-e: 1988-0847.

LEÓN-CASTRO ALONSO, José. Reflexiones en torno al matrimonio homosexual ( si alguna aún debiera caber ). Humanitas: Revista de Investigación. [En línea]. Costa Rica: Universidad Católica de Costa Rica, 2013, vol.10, n 10, p. 131-148. < http://dialnet.unirioja.es/servlet/articulo?codigo=4348155>. ISSN: 1659-1852.

LÓPEZ SÁNCHEZ, Felix. Homosexualidad y familia: lo que los padres, madres, homosexuales y profesionales deben saber y hacer. Barcelona: Graó, 2006.166 p.

MARTEL, Frederic. Global gay. Cómo la revolución gay está cambiando el mundo. Ed. Taurus. Pensamiento, 2014. 310 p.

MUÑOZ CATALÁN, Elisa. La impotencia generandi en el matrimonio romano homosexual. Foro: Revista de ciencias jurídicas y sociales. [En línea]. Madrid: Universidad Complutense de Madrid, 2013, vol. 16, $\mathrm{n}^{\circ}$ 2. < http://dialnet.unirioja.es/servlet/articulo?codigo=4721276>. ISSN: $1698-5583$.

NUEVO, Pablo. Reflexiones constitucionales sobre el llamado matrimonio homosexual. Díkaion: Revista de actualidad jurídica. [En línea]. Colombia: Universidad de la Sabana, 2006, $\mathrm{n}^{\circ}$ 15. < http://dialnet.unirioja.es/servlet/articulo?codigo=2292012>. ISSN-e: 01208942.

SEGURA GUTIÉRREZ, Jose Miguel. El sujeto homosexual, voces, poderes y vulnerabilidades. Konvergencias: Revista de Filosofía y Culturas en Diálogos. [En línea]. Argentina, 2007, no 5, p. 39-55. < http://dialnet.unirioja.es/servlet/articulo?codigo=2310337>. ISSN-e: 1669-9092.

SERENA, Marc. ¡Esto no esafricano! Valencia: Editorial Xplora, 2014. 269 p.

STYCHIN, Carl F. Same-sex sexualities and the globalization of human rights discourse. McGill Law Journal, 2003, nº 49, p. 951-968. <

http://www.lawjournal.mcgill.ca/userfiles/other/270992-4stych.pdf >. ISSN 0024-9041. 
VALDEÓN GARCÍA, Roberto.A. El tratamiento de la temática homosexual en cuatro novelistas ingleses: Lawrence, Foster, Waugh y Storey ( 1914-1963 ). Cuadernos de investigación filológica. [En línea]. Logroño: Universidad de la Rioja, 1997-1998, no 23-24, p. 139-162. < http://dialnet.unirioja.es/servlet/articulo?codigo=263901>. ISSN: 0211-0547.

WIKIPEDIA. Fecha legalización definitiva de la homosexualidad por países. 2015. <http://es.wikipedia.org/wiki/Legislación_sobre_la_homosexualidad_en_el_mundo>.

Recebido em Julho de 2016

Aprovado em Outubro de 2016

Publicado em Dezembro de 2016 